\title{
Estratégias que educadoras de creche afirmam utilizar para lidar com o choro dos bebês
}

\author{
Lígia Ebner Melchiori \\ Universidade Estadual Paulista, Bauru \\ Zélia Maria Mendes Biasoli Alves \\ Universidade de São Paulo, Ribeirão Preto
}

\begin{abstract}
RESUMO
O objetivo desse estudo é o de verificar a visão das educadoras de creche a respeito de como agem quando os bebês choram, se identificam a causa do choro e quais os motivos subjacentes que as levam a agir ou não. Vinte e uma educadoras de creche foram entrevistadas a respeito de cada um dos 90 bebês de 4 a 24 meses de idade, sob seus cuidados, segundo um roteiro semi-estruturado. Os resultados mostram que, com o aumento da idade, maior a proporção de bebês que chora pouco. O choro por necessidades primárias, na percepção das educadoras, tende a decrescer com o aumento da idade e, ao contrário, o choro por necessidades diversas tende a aumentar. As educadoras, na maioria das vezes, procuram eliminar a necessidade que causa o choro, priorizando o bem estar dos bebês. Discutem-se as práticas educativas das educadoras com os dados encontrados na literatura.
\end{abstract}

Palavras chave: creche; práticas educativas; educadoras.

\section{ABSTRACT \\ Strategies of day care center educators in dealing crying babies}

The purpose of this study is to explore the views of day care center educators on how they act when babies cry, if they are able to identify the causes of crying and what are the subjection reasons that make them take action or not. Twenty-one caretakers were interviewed about each of the ninety babies, aged 4 to 24 months, under their care, using a semi-structured guide. The results show that overall the proportion of babies that do not cry significantly increases with age. However, crying for primary needs, in the view of the educators, tends to decrease as the average age increases, whilst crying for secondary needs tends to increase. Most of the time, the educators try to eliminate the needs that provoke crying, giving priority to the baby's welfare. The article discusses the caretakers' educative practices with data found in literature.

Keywords: day care; educative practices; educators.

O tema práticas educativas não é novo. Na década de 80 houve um crescente interesse nessa área, traduzido em um acréscimo de publicações científicas a respeito de práticas educativas e de treinamento de pais. No entanto, Clark-Stewart (1998) destaca o contínuo declínio desses estudos nos EUA, a partir do final da década de 80. São eles hoje menos necessários?

Inúmeros autores trabalharam nessa área, tentando clarificar as práticas utilizadas pelos pais, ao educarem seus filhos, classificando as práticas educativas ou mesmo as famílias, em função da forma de agir e das crenças subjetivas ao comportamento parental. Belsky (1984), por exemplo, acredita que as práticas educativas são determinadas por três grandes fatores: (a) a personalidade dos pais; (b) as características das crianças e (c) a qualidade da relação marital. Russel (1997) encontrou resultados que reforçam os fatores propostos por Belsky (1984) para a análise dos cuidados dispensados às crianças pelos pais e sugeriu que, apesar disso, podem ocorrer diferenças de gênero entre mãe e pai, e entre os cuidados dispensados por cada genitor ao filho e à filha.

Uma outra autora que se destaca nessa área é Baumrind (1966; 1967; 1989). Estudando práticas educativas dos pais, a autora relaciona cuidados educativos mais punitivos com o autoritarismo, contrastando com $\mathrm{o}$ de exercer autoridade ${ }^{1}$, característica dos genitores que se caracterizam como firmes, responsivos e amorosos. Baumrind (1966) argumenta que, pais que se comportam mais de acordo com as práticas educativas em que exercem autoridade, sem serem autoritários, têm provavelmente filhos mais amigáveis, agradáveis, cooperativos e interessados em aprender do que os pais autoritários ou permissivos. Maccoby e Martin (1983) enfatizam que os pais podem ser classificados dentro de um continuum de comportamento, caracterizados de um lado por rejeição/hostilidade/baixo envolvimento com o filho e do outro por aceitação/afeto/alto envolvimento. 
Figueira (1987) e Palacios (1990) definem a família tradicional e a moderna. Na primeira está bem definido o que é certo e errado, os pais são a favor de práticas educacionais coercitivas e têm pouca predisposição para interações com seus filhos. As regras têm sua origem em uma autoridade exterior ao sujeito, a identidade de todos os membros é definida a partir de sua posição na família, sexo e idade. Na família moderna, as diferenças pessoais estão acima das diferenças posicionais, etárias e sexuais. As expectativas dos pais sobre desenvolvimento são otimistas eles acreditam que influenciam seus filhos em características que estes ainda vão adquirir. Seus membros são respeitados como iguais por serem indivíduos e, ao mesmo tempo, respeitam suas diferenças pessoais. As noções de certo e errado não são bem delineadas, uma vez que a pluralidade de escolhas é delimitada pelo respeito a individualidade do outro. A esses dois tipos Palacios (1990) acrescenta a família paradoxal. As crenças parentais são muitas vezes contraditórias, ou a ação não corresponde à crença. Os pais assim classificados têm expectativas otimistas a respeito do desenvolvimento precoce dos filhos, embora estas não os levem a interagir com eles mais cedo. Suas idéias, sobre como ajudar seus filhos, não são colocadas em prática.

Caldana (1998) destaca que o modelo de educação tradicional

pressupões regras e papéis extremamente definidos e que o moderno prima pela inexistência (ou quase) desse tipo de regras, ficando a cargo de cada um decidir sua forma de agir de acordo com suas crenças particulares e idiossincrasias; e isto, sem dúvida, reforça tanto a variabilidade das condutas como a dificuldade dos pais (p. 89).

Honig e Deters (1996), em um estudo com 63 avós e 63 filhas que eram mães de crianças pré-escolares, de famílias de classe média norte-americana, concluem que avós e filhas parecem refletir mais a prática educativa de exercer autoridade do que autoritarismo, embora as filhas sejam mais flexíveis em relação à sexualidade da criança, treino de toalete e no modo de a criança comer.

Biasoli-Alves (1995) e Biasoli-Alves e Caldana (1992), estudando mães de camada média dos centros urbanos brasileiros, concluem que, no geral, elas mantêm a estruturação da rotina, deixando um grande espaço para as decisões da criança; exigem o cumprimento de um pequeno número de normas, principalmente nas áreas de higiene e saúde; mostramse preocupadas em desenvolver a autonomia dos filhos e em "respeitar a criança", permitindo sua participação ativa nos aspectos de seu cotidiano. Em termos da disciplina, o recurso mais utilizado é o de explicar, numa prática caracterizada pelo uso preferencial das técnicas disciplinares verbais, não punitivas. Aparece o reforço para o bom comportamento, embora seja mais freqüente a presença de alguma forma de reação frente ao considerado inadequado, porém nem sempre punitiva. As mães mantêm um alto nível de expressão de afeto físico e verbalmente e consideram importante a proximidade através do brincar, estando atentas a possíveis sofrimentos e problemas emocionais do filho, de que os comportamentos inadequados seriam indicativos. Caldana (1998), discutindo esses dados, acrescenta que essa descrição "sugere a assimilação de um ideário anti-autoritário, permeado por idéias ligadas à Psicologia e a Psicanálise, compondo uma prática centralizada na criança" (p. 88), evidenciando as preocupações das mães com o desenvolvimento da autonomia e da independência de seus filhos.

Dias da Silva (1991) também conclui que, no Brasil, da década de 30 para a de 80 , houve um aumento progressivo da valorização da independência da criança, na população de camada média. Baumrind (1966) destaca a importância de se enfatizar a independência progressiva por parte da criança, sem que lhe deixem de ser colocados alguns limites.

Caldana (1998) ressalta que, apesar das variações, "a educação da criança atualmente a coloca numa posição privilegiada perante o adulto preocupado em fazê-la feliz, em respeitar a sua individualidade, em diminuir a distância entre ambos" (p. 90).

Apesar dessa alteração positiva na educação dos filhos de classe média, esses mesmos autores ressaltam que os pais atualmente estão vivendo momentos de incerteza em relação a qual a melhor maneira de educar seus filhos (Biasoli-Alves, 2000; Biasoli-Alves, Caldana \& Dias da Silva, 1997; ClarkStewart, 1998). Biasoli-Alves (1995) ressalta que o modelo atual de ideário de educação vem de uma evolução em que, em um primeiro momento, foi questionado o excesso de controle e, em um segundo momento, o oposto, a falta de controle e limites. Essa autora diz que

\begin{abstract}
as mães relataram que perdem a paciência, gritam $e$, se a criança não obedece, elas fazem algum tipo de ameaça... os dados evidenciam que elas, hoje, mostram-se mais irritadas e apressadas e querem que o filho cumpra seu compromisso, sem trazer muitas dificuldades para um cotidiano já conturbado (Biasoli-Alves, 2000, p. 237).
\end{abstract}

Diante desse contexto, temos que concordar com Clark-Stewart (1998). Em seu levantamento histórico sobre temas e idéias a respeito do cuidado de crianças nos EUA, ele conclui que, embora as atitudes dos pais em relação à punição dos filhos têm sido menos severas, ainda há fortes divergências sobre a melhor forma de se educar crianças.

Há necessidade de mais estudos também no Brasil, inclusive abrangendo outras classes sociais, áreas urbanas e suburbanas em diferentes regiões do país para maior clareza das práticas educativas utilizadas nesse país e suas decorrências. Analisando-se às práticas educativas utilizadas por educadoras brasileiras com as crianças de zero a três anos que freqüentam creches, esses estudos praticamente inexistem. Hoje essa área de estudo é de extrema relevância porque cada vez mais crianças brasileiras, de diferentes camadas sociais, são levadas para creches e berçários, desde bebês. Caldwell (1995) 
enfatiza que o bebê do século XXI precisa de um sistema de apoio suplementar ao da família, e que tenha qualidade, porque a ele será atribuído um papel de extrema relevância. Sem dúvida se está diante de transformações sociais nos sistemas de valores que atingem diretamente a vida dos bebês (Bronfenbrenner, 1985; Dencik, 1994; Lordelo, 1997, 2002).

A necessidade de conhecer e avaliar ambientes coletivos em seus múltiplos aspectos tem sido objeto de estudo de vários pesquisadores brasileiros (Anjos, Amorim \& Rossetti-Ferreira, 2002; Araújo, Almeida \& Gil, 2002; Melchiori \& Biasoli-Alves, 2001; Melchiori \& cols., 2003; Oliveira, Furtado, Souza \& Carvalho, 2003; Vieira, Guimarães, Toledo, Reis \& Andrade, 2003, entre outros).

Como serão as práticas educativas das educadoras de ambiente coletivo? Uma grande lacuna, na literatura, é a respeito de como as educadoras de creches, berçários, hoteizinhos, se comportam com os bebês sob seus cuidados. Quais serão as estratégias utilizadas por elas para lidarem com os bebês sob seus cuidados? Elas incentivam a autonomia dos bebês ou procuram controlá-los para manter a ordem dentro do berçário? Quais os motivos subjacentes por trás das suas ações com os bebês? O objetivo desse estudo é o de tentar clarificar algumas dessas perguntas em uma situação específica: quando os bebês choram. Como elas acham que agem quando o bebê chora? Segundo elas, há tentativas de identificar o motivo do choro? Procuram agir de forma diferente em função disso? As práticas utilizadas pelas educadoras com certeza influenciarão no comportamento social das crianças sob seus cuidados, uma vez que estas passam de 4 a 10 horas diárias dentro do ambiente coletivo, em contato com elas.

\section{MÉTODO \\ Sujeitos}

Colaboraram para a realização desse estudo 21 educadoras de creche, do sexo feminino, com idades variando de 21 a 57 anos, tendo entre três a 18 anos de experiência no cuidado de bebês, na instituição em que os dados foram coletados. Vinte e quatro porcento das educadoras possuíam o primeiro grau completo, $57 \%$ o segundo grau completo e o restante (19\%), o segundo grau incompleto. Elas cuidavam de 90 bebês de 4 a 24 meses de idade, sendo $49 \%$ do sexo feminino e $51 \%$ do sexo masculino, todos filhos de funcionárias de um hospital universitário, com nível de escolaridade variando do primeiro grau ao superior. A profissão das mães incluía desde faxineira até médicas e administradoras.

\section{Local}

O trabalho foi desenvolvido no berçário de um Centro de Convívio Infantil ligado a um hospital público universitário de uma cidade do interior paulista. Essa creche atende bebês e crianças de quatro meses a sete anos incompletos, filhos de funcionárias do hospital, que trabalham de quatro a 10 horas diárias, sendo que a maioria da clientela permanece na creche em período integral. O trabalho foi desenvolvido na própria creche, com todas as educadoras que trabalhavam no berçário com bebês de 4 a 24 meses.

\section{Procedimento}

Foi elaborado um roteiro para entrevista semiestruturada, solicitando que as educadoras descrevessem o comportamento de cada bebê durante o período em que ele se encontrava na creche, incluindo: (a) a chegada - quando o bebê era trazido pela mãe, pai ou ambos; (b) a alimentação mamadeira ou seio, suco, fruta, refeições; (c) o processo de higienização - troca de fraldas e banho; (d) a saída da creche. Além disso, foi verificado em que situações cada um dos 90 bebês choravam, como era o choro, como as educadoras agiam quando eles choravam em cada uma das situações levantadas e porque agiam assim. A entrevista semi-estruturada, composta dos tópicos acima, foi escolhida porque

\begin{abstract}
permite uma formulação flexível e a seqüência $e$ minuciosidade ficam por conta do discurso dos sujeitos e da dinâmica que acontece naturalmente. As questões nesse caso são abertas e devem 'evocar' ou 'suscitar' uma verbalização que expresse o modo de pensar ou de agir das pessoas face aos temas focalizados; freqüentemente elas dizem respeito a uma avaliação de crenças, sentimentos, valores, atitudes, razões e motivos acompanhados de fatos e comportamentos (Biasoli-Alves, 1998, p. 145).
\end{abstract}

\section{Coleta de dados}

As educadoras foram entrevistadas na própria creche, durante o período de trabalho e, em cada entrevista, eram solicitadas a focalizar um bebê de 
cada vez, dentre os 4 ou 5 sob seus cuidados mais diretos. Foram realizadas 90 entrevistas com as 21 educadoras, com a duração média de meia hora, totalizando 45 horas de gravação em áudio.

\section{Análise dos dados}

As entrevistas foram transcritas na íntegra e, em seguida, os dados foram analisados de forma quantitativa e quantitativa-interpretativa (BiasoliAlves, 1998). De forma quantitativa quando eram extraídos diretamente da fala das educadoras, pois a leitura fornecia a unidade de análise. De forma quantitativa-interpretativa quando foram construídos sistemas de categorias para o relato das educadoras, obedecendo-se aos seguintes critérios: o de exaustividade, o de exclusividade, o nível de amplitude das categorias e o nível de inferência das categorias (Sigolo \& Biasoli-Alves, 1998).

\section{Resultados}

Buscou-se inicialmente classificar a frequiência do choro dos bebês no relato das educadoras, analisar então os motivos que elas apontavam para o choro, para depois identificar as estratégias utilizadas para lidar com este comportamento.

O choro foi classificado em relação a sua freqüência, sendo colocado em três categorias: (a) chora muito - quando as educadoras comentavam que a criança era chorona; (b) chora dentro de um padrão médio para a idade - quando comentavam que o choro era dentro de um padrão normal, geralmente ligado a alguma necessidade básica como fome, sono, dor e; (c) chora pouco - quando as educadoras comentavam que era uma criança que quase não chorava. A Figura 1 traz a porcentagem da classificação do choro dos bebês e crianças.

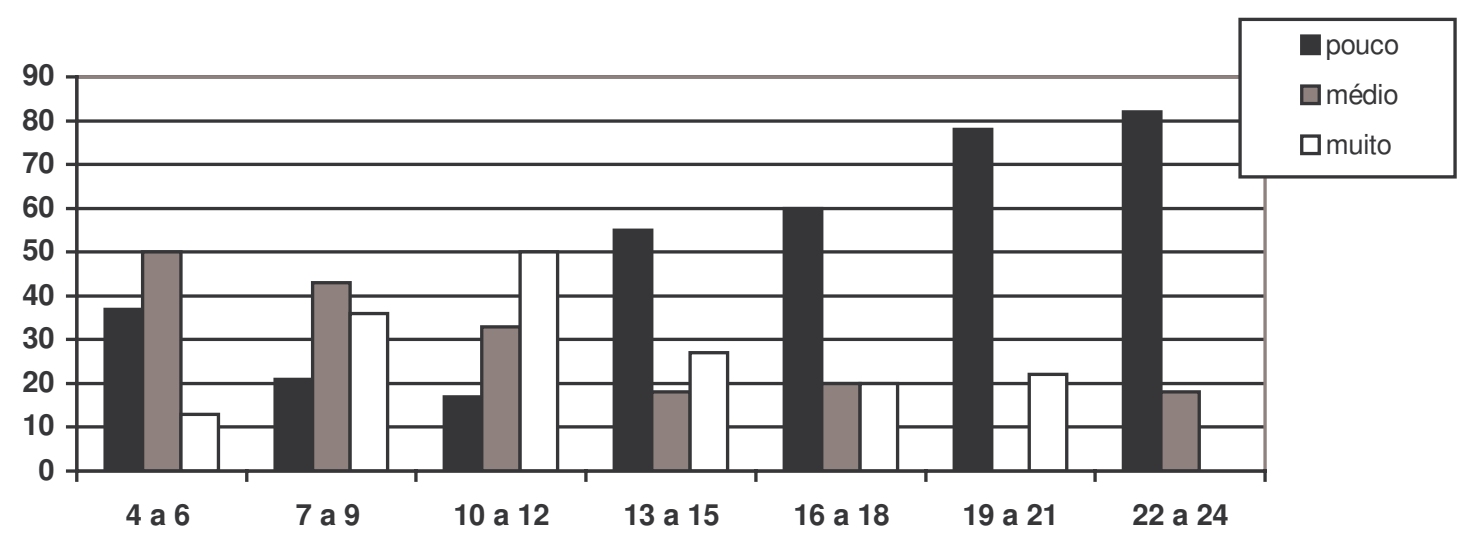

Figura 1: Porcentagem da classificação do choro de bebês, de quatro a 24 meses de idade, segundo a visão das educadoras.

Os dados indicam que metade dos bebês mais novos (de 04 a 06 meses) foi julgada como chorando dentro de um padrão médio para a idade, e mais de um quarto (37\%) chora pouco; dos bebês de sete a noves meses de idade, quase metade chora dentro de um padrão considerado normal pelas educadoras e $36 \%$ chora muito. Metade dos bebês de 10 a 12 meses chora muito e $33 \%$ chora dentro de padrão normal; e mais da metade (55\%) dos bebês de 13 a 15 meses de idade chora pouco. Com o aumento da idade, maior a proporção de crianças que chora pouco.

Em seguida, foram categorizados os motivos pelos quais os bebês choram, se por necessidades primárias ou diversas. O motivo do choro foi considerado como ocorrendo por necessidades primárias quando os bebês apresentavam fome, sono, dor ou mal estar físico, frio ou calor. $\mathrm{O}$ motivo do choro foi considerado como ocorrendo por necessidades diversas por dezoito motivos diferentes: (a) quando as educadoras comentavam que era porque eles se sentiam só; (b) quando a mãe afastava-se; (c) quando a educadora afastava-se; (d) quando o bebê se assustava ou rejeitava o banho; (e) quando agredido fisicamente por outros bebês ou quando eles lhe tiravam objetos (chupeta, brinquedo, fralda etc.); (f) quando as educadoras tiravam algum objeto de suas mãos; (g) quando caiam; (h) quando eram colocados no chão; (i) quando eram colocado perto de outros bebês; (j) quando estavam molhados ou sujos (cocô ou xixi); (k) quando eram acordados por algum motivo ou acordavam ainda com sono; (1) quando queriam mudar de posição ou local (ex: sair da posição deitada, sair do quadrado); (m) quando na presença de estranhos; (n) quando viam a mãe; (o) quando queriam colo ou não queriam sair do colo; (p) quando era necessário desobstruir seu nariz; (q) quando a educadora tirava de uma situação específica (ex: para trocar, dar banho, separar da situação em que estava agredindo etc.); (r) quando queriam algo que estava com outro bebê. As educadoras também colocaram que algumas vezes não conseguem identificar a causa do choro.

A Figura 2 traz a visão das educadoras sobre os motivos do choro dos bebês de quatro a vinte e quatro meses de idade. 


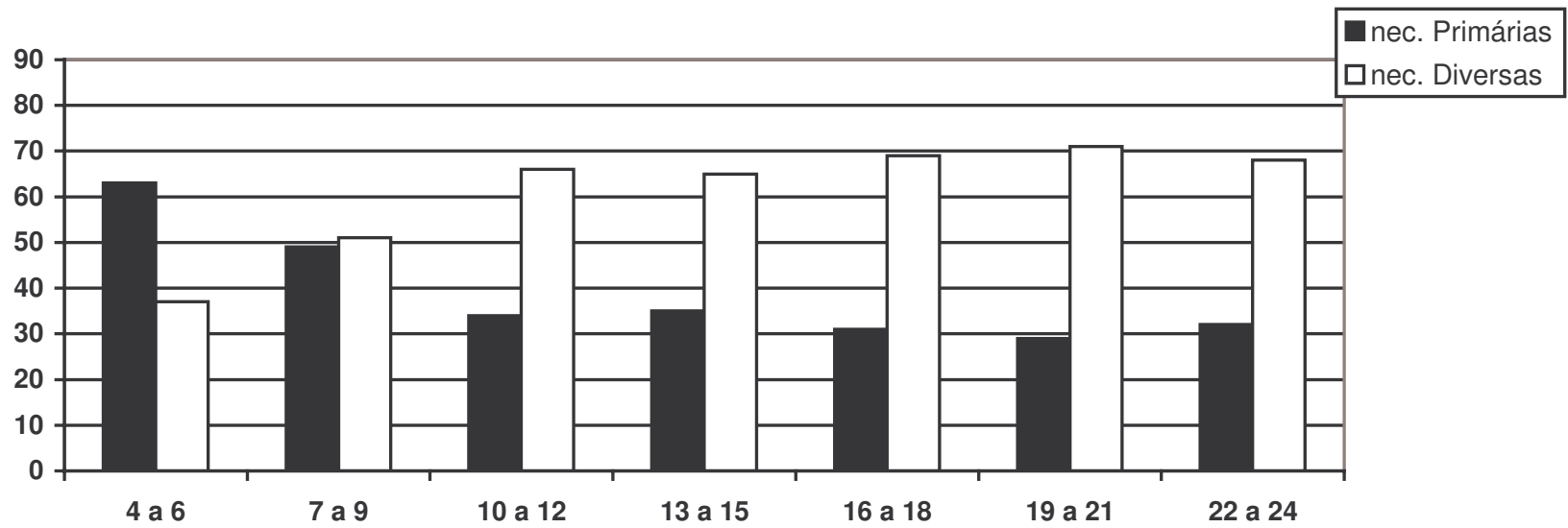

Figura 2: Porcentagem de choro, por necessidades primárias ou diversas, de bebês de quatro a 24 meses de idade, segundo a visão das educadoras.

Pode-se observar que o choro por necessidades primárias, na percepção das educadoras, tende a decrescer com o aumento da idade e, ao contrário, o choro por necessidades diversas tende a aumentar.

Após ser identificada a freqüência do choro dos bebês e os motivos pelos quais eles choram, segundo a opinião das educadoras, procedeu-se a análise de quais são as estratégias que elas utilizam para lidar com o choro deles. Esses dados foram analisados segundo duas amplas categorias: quando a educadora identifica ou não a causa do choro.

Quando as educadoras identificam a causa do choro, foram detectados três conjuntos de comportamentos por parte delas. Elas procuram agir seja no sentido de: (a) eliminar a causa do choro, suprindo a necessidade ou falta, como, por exemplo, dando comida quando o bebê está com fome; (b) eliminar o choro, independentemente de não conseguirem sanar o que o provoca, distraindo-os, oferecendo condições de conforto ou apressando a ação que causa o choro, ou ainda (c) não se preocupar com o choro apresentado pelos bebês, observando-o primeiro e só intervindo quando necessário ou não atender porque a educadora tirou-o de uma situação em que estava agredindo o outro, por exemplo.

A Tabela 1 traz as estratégias que as educadoras dizem utilizar para atender ao choro dos bebês quando identificam que eles ocorrem por necessidades primárias.

Tabela 1: Porcentagem das estratégias que as educadoras dizem utilizar para lidar com o choro dos bebês quando julgam que eles ocorrem por necessidades primárias

\begin{tabular}{|c|c|c|c|c|}
\hline \multicolumn{2}{|c|}{ ESTRATÉGIAS UTILIZADAS } & Terminar com o desconforto & Distrair & Dar condições de conforto \\
\hline \multirow{4}{*}{ 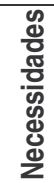 } & Fome & 31 & 10 & \\
\hline & Sono & 28 & 06 & 03 \\
\hline & Dor/Mal estar & 21 & & \\
\hline & Frio/Calor & 01 & & \\
\hline \multicolumn{2}{|c|}{ TOTAL } & 81 & 16 & 03 \\
\hline
\end{tabular}

Os dados mostram que as educadoras sempre julgam identificar a causa do choro quando acreditam que ele ocorra por necessidades primárias. $\mathrm{Na}$ maior parte das vezes $(81 \%)$ elas procuram eliminar a necessidade, alimentando o bebê, colocando-o para dormir etc. Quando não é possível eliminar a causa do choro imediatamente ( $16 \%$ das vezes) elas procuram distrair o bebê, cantando, mostrando objetos etc. Quando os bebês estão com sono, uma educadora acha que colocá-los para dormir é suficiente, e deixaos chorando até que durmam.
Quando as educadoras não conseguem identificar a causa do choro, elas agem no sentido de: (a) eliminar o choro distraindo o bebê como, por exemplo, pegando-o no colo, mostrando brinquedos, conversando, cantando; (b) não se preocupar com o choro, deixando-o chorando, não tomando nenhuma atitude que vise fazê-lo parar de chorar.

A Tabela 2 traz as estratégias que as educadoras dizem utilizar para atender o choro dos bebês causado por necessidades diversas.

Tabela 2: Porcentagens das estratégias que as educadoras dizem utilizar para lidar com o choro de bebês quando julgam que ele ocorre por necessidades diversas

\begin{tabular}{l|c|c|c|c|c}
\hline Situações & \multicolumn{3}{|c|}{$\begin{array}{c}\text { Quando a educadora identifica } \\
\text { a causa do choro }\end{array}$} & \multicolumn{2}{c}{$\begin{array}{c}\text { Quando a educadora não } \\
\text { identifica a causa do choro }\end{array}$} \\
\hline Objetivo & $\begin{array}{c}\text { Tenta eliminar } \\
\text { causa }\end{array}$ & $\begin{array}{c}\text { Tenta eliminar } \\
\text { choro }\end{array}$ & Não se preocupa & $\begin{array}{c}\text { Tenta eliminar } \\
\text { choro }\end{array}$ & $\begin{array}{c}\text { Não se preocupa } \\
\text { chocher }\end{array}$ \\
\hline
\end{tabular}




\begin{tabular}{|c|c|c|c|c|c|c|c|c|}
\hline & Estratégias utilizadas & $\begin{array}{l}\text { Terminar com } \\
\text { o desconforto }\end{array}$ & Distrair & $\begin{array}{c}\text { Apressar } \\
\text { ação que } \\
\text { causa o choro }\end{array}$ & $\begin{array}{l}\text { Observar } \\
\text { primeiro }\end{array}$ & $\begin{array}{l}\text { Não } \\
\text { atender }\end{array}$ & Distrair & Não atender \\
\hline \multirow{19}{*}{ 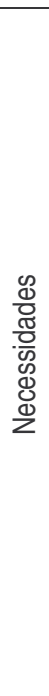 } & Sente-se só & 06 & & & & & & \\
\hline & A mãe se afasta & 08 & & & & & & \\
\hline & A educadora se afasta & 04 & & & & & & \\
\hline & Se assusta e rejeita o banho & & 04 & 03 & & & & \\
\hline & Agredido/tiram objeto & 20 & 01 & & 03 & & & \\
\hline & Educadora tira objeto & & 01 & & & 01 & & \\
\hline & Cai & & 03 & & & & & \\
\hline & Colocado no chão & 02 & 01 & & & & & \\
\hline & Perto de outros bebês & 06 & & & & & & \\
\hline & Molhado ou sujo & 01 & & & & & & \\
\hline & E acordado ou acorda c/sono & 06 & & & & & & \\
\hline & Quer mudar de posição/local & 07 & & & & & & \\
\hline & Na presença de estranhos & 04 & & & & & & \\
\hline & Vê a mãe & 01 & & & & & & \\
\hline & Quer colo/não quer sair do colo & 04 & 02 & & & & & \\
\hline & Desobstruem seu nariz & & & 01 & & & & \\
\hline & A educadora tira da situação & & 01 & & & 01 & & \\
\hline & Quer algo que está com o outro & 01 & 01 & & & 01 & & \\
\hline & Não identificado & & & & & & 04 & 02 \\
\hline & Subtotal & 70 & & 18 & 0 & & & \\
\hline & Total & & & 94 & & & & \\
\hline
\end{tabular}

Os dados mostram que quando as necessidades são diversas, as educadoras julgam identificar a causa do choro em $94 \%$ das vezes e que, quando a causa é identificada, na maior parte das vezes $(73 \%)$ há a preocupação em suprir a necessidade ou falta, eliminando a causa do choro. Em alguns casos, como quando tiram um objeto do bebê ou ainda quando ele é colocado no chão, as educadoras procuram distraílo. Quando o bebê se assusta ou rejeita o banho, elas procuram apressar a higienização. Somente em 6\% das vezes, as educadoras não se preocupam com o choro, ou porque primeiro observam se o bebê reage e se defende quando the tiram um objeto, por exemplo, ou porque julgam que é educativo não atender o bebê naquele momento. Quando as educadoras não conseguem identificar a causa do choro, agem geralmente procurando distrair o bebê e algumas vezes deixam-no chorar, porque acham que vai parar em seguida ou porque acreditam que nada do que fizerem vai interromper o choro.

Também se procurou identificar, na fala das educadoras, os motivos que as levaram a utilizar cada uma das estratégias acima citadas, visando o atendimento ou não das necessidades dos bebês quando choram. A análise dos dados indicou seis explicações para a utilização dessas estratégias, que estão diretamente vinculadas: (a) ao bem estar do bebê; (b) à obediência à ordem da mãe; (c) ao nível de ocupação da educadora; (d) à crença da educadora; (e) ao julgamento do comportamento do bebê pela educadora; (f) à prioridade de atender primeiramente outra necessidade.

Em relação à primeira explicação, que visa $o$ bem estar do beb̂e, estão as ações que eliminam ou suprem a necessidade do bebê, implicando em fazê-lo até a eliminação do choro como, por exemplo, alimentar o bebê quando com fome; dar banho rápido (quando o bebê rejeita o banho); colocar para dormir e esperar até que se aquiete; aquecer a barriguinha, fazer massagem, dar alguma medicação para eliminar a dor; brincar, pegar no colo, conversar, até que pare de chorar, quando se sente só ou a mãe se afasta; tirar de perto de outros bebês ou mudar de posição quando desejar.

Quando a estratégia está em função de obediência à ordem da mãe do bebê, implica respeitar a ordem da mãe e não alimentar o bebê porque ela quer alimentálo pessoalmente ou o comportamento inverso, alimentá-lo caso ele esteja chorando e a mãe não tenha chegado.

Às vezes as estratégias têm como causa o nível de ocupação da educadora, que é o de fazer alguma ação que não elimina a causa do choro, mas que distraia o bebê, até a educadora poder terminar o que está fazendo e atender a necessidade dele mais diretamente, como, por exemplo, distrair o bebê que está com fome, conversando com ele, pedindo que busque algum brinquedo, enquanto alimenta outro bebê.

Algumas vezes, as ações estão baseadas na crença das educadoras, que implicam acreditar que dar condições para o bebê suprir sua necessidade é suficiente, não necessitando, por exemplo, ficar ao seu lado até que pare de chorar na hora de dormir, porque isso vai acontecer naturalmente; ou deixar o bebê se defender, em caso de agressão ou de tentarem pegar seu brinquedo e, só intervir se ele não conseguir resolver a situação sozinho, porque acreditam que o bebê precisa aprender a se defender e adquirir autonomia; ou ainda por necessidade de colocar limites, como por exemplo no caso de deixar a criança chorar porque precisa aprender que não pode ter tudo o que quer (quando quer um objeto que está com outra criança ou quando a educadora tira dele um objeto que ele pegou do outro ou ainda porque a educadora tira-o de uma situação em que ele estava agredindo o outro).

Quando a ação está baseada no julgamento do comportamento do bebê pela educadora, ela não faz nada para cessar o choro porque acha que independente do que fizer o bebê vai continuar 
chorando ou vai parar logo em seguida, baseado nos comportamentos emitidos por ele no dia a dia da creche.

Outras vezes, a ação das educadoras está baseada na prioridade de atender primeiramente outra necessidade, como por exemplo, apesar de identificar a necessidade de sono, tenta manter o bebê acordado para alimentá-lo.

A Tabela 3 traz os motivos que influenciaram as estratégias utilizadas pelas educadoras, segundo elas, ao atenderem aos bebês quando choram.

Tabela 3: Porcentagem de motivos subjacentes às estratégias que as educadoras dizem utilizar para lidar com o choro dos bebês

\begin{tabular}{|c|c|c|c|c|c|c|c|c|c|c|}
\hline \multicolumn{2}{|c|}{$\begin{array}{l}\text { Motivo da utilização das estratégias para lidar com } 0 \\
\text { choro é veiculado } \mathrm{a}(0)\end{array}$} & $\begin{array}{l}\text { Bebês } \\
4-6 \mathrm{~m}\end{array}$ & $\begin{array}{l}\text { Bebês } \\
7-9 \mathrm{~m}\end{array}$ & $\begin{array}{c}\text { Bebês } \\
10-12 m\end{array}$ & $\begin{array}{c}\text { Bebês } \\
13-15 m\end{array}$ & $\begin{array}{c}\text { Bebês } \\
16-18 m\end{array}$ & $\begin{array}{c}\text { Bebês } \\
19-21 \mathrm{~m}\end{array}$ & $\begin{array}{c}\text { Bebês } \\
22-24 m\end{array}$ & $\begin{array}{l}\text { SUB- } \\
\text { TOTAL }\end{array}$ & TOTAL \\
\hline \multicolumn{2}{|c|}{ Bem estar do bebê } & 09 & 16 & 20 & 09 & 13 & 10 & 09 & 86 & 86 \\
\hline \multirow[b]{2}{*}{ Ordem da mãe } & $\begin{array}{l}\text { Esperá-la porque ela vai } \\
\text { alimentar o bebê }\end{array}$ & 03 & 0,5 & & & & & & 3,5 & \multirow[b]{2}{*}{04} \\
\hline & $\begin{array}{l}\text { Alimentar o bebê se ele chorar } \\
\text { e ela não tiver chegado }\end{array}$ & & 0,5 & & & & & & 0,5 & \\
\hline \multicolumn{2}{|c|}{ Nível de ocupação da educadora } & & & & 01 & & 0,5 & & 1,5 & 1,5 \\
\hline \multirow[b]{3}{*}{ Crença da educadora } & $\begin{array}{l}\text { Dar condições de conforto é } \\
\text { suficiente }\end{array}$ & 01 & 01 & 0,5 & & & & & 2,5 & \multirow{3}{*}{5,5} \\
\hline & $\begin{array}{l}\text { Deixar a criança ter } \\
\text { oportunidade de se defender }\end{array}$ & & & & 0,5 & & 01 & 0,5 & 2,0 & \\
\hline & Necessidade de colocar limites & & & & & 01 & 01 & & 2,0 & \\
\hline \multicolumn{2}{|c|}{ Julgamento do comportamento do bebê } & & & 0,5 & 0,5 & & & & 1,0 & 1,0 \\
\hline \multicolumn{2}{|c|}{$\begin{array}{l}\text { Prioridade de atender primeiramente outras } \\
\text { necessidades }\end{array}$} & & & & 0,5 & 0,5 & & & 1,0 & 1,0 \\
\hline
\end{tabular}

Os dados mostram que a maioria das estratégias utilizadas pelas educadoras ocorre visando o bem estar dos bebês $(86 \%)$ em todas as faixas etárias. As estratégias que exercem, em função da ordem da mãe, só ocorrem nas primeiras faixas etárias, uma vez que a mãe só vai alimentar seu bebê nos primeiros meses em que ele está na creche, principalmente enquanto amamenta no seio, com ou sem complementação da mamadeira e de outros tipos de alimentos. A estratégia que tem como base a crença de que dar condições de conforto para o bebê dormir quando com sono deixá-lo chorando é adequado ou suficiente só foi citada por uma educadora. A crença de que deve dar oportunidades para o bebê se defender ou de que deve impor limites, começou a ocorrer com bebês com mais de um ano de idade. A explicação de que a educadora está ocupada com outra atividade e não pode atender o bebê começa a aparecer dos 13 meses em diante. Além desses motivos, também ocorreu de a educadora comentar que há bebês que independentemente do que elas fizerem para evitar, vão continuar chorando ou vão parar de chorar em seguida e de que, às vezes, a educadora não pode atender a necessidade do bebê de dormir, por exemplo, porque, naquele momento, prioriza alimentá-lo.

\section{DISCUSSÃO}

Nesse estudo, pode-se observar que, com o aumento da idade, aumenta também a proporção de bebês que chora pouco, indicando uma possível adaptação à situação de convivência em ambiente coletivo.

A faixa etária intermediária, dos 10 aos 12 meses, é a única em que metade dos bebês chora muito, predominando nas faixas anteriores o padrão médio de choro e, nas posteriores, o chorar pouco. A esse respeito, Melchiori (1999), analisando o comportamento dos bebês em situações rotineiras da creche, comenta que a faixa dos "8 aos 12 meses, aproximadamente, parece ser um período de transição entre os comportamentos apresentados pelos bebês mais novos e pelos mais velhos..." (p. 84).

O presente estudo também mostrou que, na medida em que os bebês vão ficando mais velhos, o choro por necessidades básicas diminui, aumentando o choro por necessidades diversas. Nessas situações, as educadoras geralmente agem no sentido de eliminar a causa do choro e, quando isso não é possível, procuram distrair os bebês ou apressar a ação que causa o choro, tentando fazê-lo cessar, indicando que, na maior parte das vezes, há a preocupação com o bem estar dos bebês sob seus cuidados.

As educadoras também comentaram que, às vezes, não se preocupam com o choro, tendo ou não identificado seu motivo, visando dar uma chance de a criança se defender do colega agressor ou que está tentando pegar algum objeto de sua mão, procurando observar se reagem, se defendem, e só intervindo se necessário. Essa preocupação com a autonomia da criança também foi encontrada na literatura (Caldana, 1998; Dias da Silva, 1991; Biasoli-Alves, 1995; Biasoli-Alves \& Caldana, 1992), a respeito das práticas educativas de pais de camada média da população brasileira.

Além dessa preocupação com a independência da criança, também aparece nitidamente a colocação de limites em situações que as educadoras retiram objeto que um bebê tomou do outro à força, ou retiram-no da situação em que está sendo o agressor. Essa ação das educadoras, aliada à forma tranquiila de elas relatarem essas situações, encarando o comportamento dos agressores com muita serenidade, preocupadas com o aprendizado deles e não porque julgam que são terríveis ou malvados, vem de encontro com as colocações de Baumrind (1966) a respeito de práticas educativas, salientando a necessidade de afeto e da colocação de limites, no modelo de autoridade, ao contrário 
autoritarismo, onde os pais são inflexíveis, deixando pouco espaço para a criança ter liberdade de tomar algumas decisões.

$\mathrm{Na}$ análise dos motivos subjacentes às estratégias utilizadas pelas educadoras para lidar com o choro dos bebês, ficou demonstrado que, na maioria das vezes $(86 \%)$ elas agem procurando proporcionar bem estar ao bebê. Em 4\% das vezes elas atuam respeitando a ordem da mãe, mesmo que contrárias à vontade delas, totalizando $90 \%$ de suas ações.

Melchiori e Biasoli-Alves (2002), em um estudo com bebês de 4 a 24 meses de idade, encontraram que, de modo geral, eles se acham adaptados à situação coletiva: apreciam o banho de sol; alimentam-se bem e passam a esperar pela papa salgada com mais tranqüilidade, brincando e se locomovendo no berçário; o sono é calmo e considerado numa quantidade normal; demonstram aceitação na troca de fraldas e no banho; permanecem em espaços amplos nas atividades livres e, com o aumento da idade, apresentam maior participação nas atividades interativas com outros bebês. Nesse presente estudo, que analisa o outro lado, ou seja, as estratégias das educadoras para lidar com o choro dos bebês, elas parecem tranqüilas e seguras na forma de agir, comentando que às vezes deixam o bebê chorando sim e porque o fazem, mas mostrando sua preocupação em evitar esse choro, seja ele causado por necessidades primárias ou diversas.

É claro que essa é a situação particular de uma creche, e não se pode dizer que em todos os ambientes coletivos a situação será semelhante. Há necessidade de outros estudos para a obtenção de dados mais abrangentes.

Melluish (2001) salienta que, no segundo milênio, tem sido confirmada a importância da qualidade dos cuidados e educação nos primeiros anos de vida do bebê e em sua educação pré-escolar. Esse autor acrescenta que, as atuais estratégias, estão se direcionando cada vez mais para o estudo da qualidade desses ambientes coletivos, tendo em vista não mais a visão de especialistas, mas sim, a ligação direta com os resultados no desenvolvimento das crianças. Torna-se necessário investir muito em estudos sobre creches, em função da tendência mundial desses ambientes coletivos serem cada vez mais freqüentados e, torna-se também, cada vez mais necessário, estudos que visem a integração da qualidade das creches e a experiência das crianças com a Psicologia do Desenvolvimento.

\section{Referências}

Anjos, A. M.; Amorim, K.S. \& Rossetti-Ferreira, M.C. (2002). Processos interativos de crianças abaixo de dois anos em creche- necessidade de ampliação do conceito de interação. Em Sociedade Brasileira de Psicologia (Org.), Anais da XXXII Reunião Anual de Psicologia (pp. 208-209). Florianópolis: SBP.

Araújo, P. M.; Almeida, N .F. \& Gil, M. S. C. A. (2002). Identificação de padrões na interação educador-criança. Em Sociedade Brasileira de Psicologia (Org.), Anais da XXXII Reunião Anual de Psicologia (p. 207). Florianópolis: SBP.

Baumrind, D. (1966). Effects of authoritative parental control in children behavior. Child Development, 37, 887-907.
Baumrind, D. (1967). Child care practices anteceding three patterns of preschool behavior. Genetic Psychology Monographs, 75, 43-88.

Baumrind, D. (1989). Rearing competent children. Em W. Damon (Org.), Child development today and tomorrow (p. 349-378). San Francisco: Jossey-Bass.

Belsky, J. (1984). The determinants of parenting: a process model. Child Development, 55, 83-96.

Biasoli-Alves, Z. M. M. (1995). Família, socialização, desenvolvimento: as práticas de educação da criança. Tese de Livre Docência não publicada, Universidade de São Paulo. Ribeirão Preto, SP.

Biasoli-Alves, Z. M. M. (1998). A pesquisa em Psicologia análise de métodos e estratégias na construção de um conhecimento que se pretende científico. Em G. Romanelli \& Z. M. M. Biasoli-Alves (Orgs.), Diálogos Metodológicos sobre Prática de Pesquisa (pp. 135-157). Ribeirão Preto: Legis Summa.

Biasoli-Alves, Z. M. M. (2000). Continuidade e rupturas no papel da mulher brasileira no século XX. Psicologia: Teoria $e$ Pesquisa, 16(3), 233-239.

Biasoli-Alves, Z. M. M. \& Caldana, R. H. L. (1992). Práticas educativas: a participação da criança na determinação de seu dia a dia. Psicologia: Teoria e Pesquisa, 8(2), 231-242.

Biasoli-Alves, Z. M. M., Caldana, R. H. L. \& Dias da Silva, M.H.G.F. (1997). Práticas de educação da criança na família: a emergência do saber técnico científico. Revista Brasileira de Crescimento e Desenvolvimento Humano, 7, 49-62.

Bronfenbrenner, U. (1985, may). The three worlds of childhood. Principal, 7-11.

Caldana, R. H. L. (1998). A criança e sua educação na família no início do século: autoridades, limites e cotidiano. Temas em Psicologia, 6(2), 87-193.

Caldwell, B. (1995). Creche - bebé, família e educação. Em J. Gomes Pedro (Org.) Bebé XXI - crianca e família na viragem do século (pp. 465-485). Lisboa: Fundação Calouste Gulbenkian.

Clark-Stewart, K. A. (1998). Historical shifts and underlying themes in ideas about rearing young children in the United States: Where have we been? Where are we going? Early Development and Parenting, 7, 101-117.

Dencik, L. (1994, july). Modern childhood in the Nordic countries: some implications of the dual socialization of children growing up according to the Scandinavian welfare state model. Trabalho apresentado no 23rd. International Congress of Applied Psychology. Madrid, Spain.

Dias da Silva, M. H. (1991). Da palmada à psicologia aplicada: a educação dos filhos pequenos nos últimos 50 anos. Araraquara: Gráfica da UNESP.

Figueira, S. A. (1987). Uma nova família? O moderno e o arcaico da família de classe média brasileira. Rio de Janeiro: Zahar.

Honig, A. S. \& Deters, K. (1996). Grandmothers and mothers: An intergenerational comparison of child-rearing practices with pre-schoolers. Early Development and Parenting, 5(1), 47-55.

Lordelo, E. R. (1997). Efeitos da experiência da creche no desenvolvimento da criança: Uma Revisão. Psicologia: Teoria e Pesquisa, 13(2), 221-229.

Lordelo, E. R. (2002). "Agora vá com a tia que a mamãe vem mais tarde": Creche como contexto brasileiro de desenvolvimento. Em E. R. Lordelo, A. M. A.Carvalho \& S. H. Koller (Orgs.), Infância brasileira e contextos de desenvolvimento (pp. 77-97). Salvador, Ba: EDUFBA e São Paulo, SP: Casa do Psicólogo.

Maccoby, E. \& Martin, J. (1983). Socialization in the context of the family: Parent-child interaction. Em E.M. Hetherington; P.H. Mussen (Orgs.), Handbook of child psychology: Socialization, personality and social development (4a ed., p.1101). New York: Wiley.

Melchiori, L. E. (1999). Desenvolvimento e comportamento de bebês (de 0 a 2 anos) na rotina diária, segundo a visão das educadoras de ambiente coletivo. Tese de Doutorado, Programa de Pós-Graduação em Psicologia, Universidade de São Paulo. Ribeirão Preto, SP. 
Melchiori, L. E. \& Biasoli-Alves, Z. M. M. (2001). Crenças de educadoras de creche sobre temperamento e desenvolvimento de bebês. Psicologia: Teoria e Pesquisa, 17(3), 285-292.

Melchiori, L. E. \& Biasoli-Alves, Z. M. M. (2002). Comportamento de bebês na rotina diária da creche. Revista Brasileira de Desenvolvimento e Crescimento Humano, 12(2), 39-51.

Melchiori, L. E.; Lotti, B. R.; Gigliotti, C. M.; Cestari, K.; Kusumi, P. \& Rodrigues, O. P. R. (2003). Como está o desenvolvimento de bebês que freqüentam creches municipais? Em Sociedade Brasileira de Psicologia (Org.), Anais da XXXIII Reunião Anual de Psicologia (p. 161). Belo Horizonte: SBP.

Melluish (2001). The quest for quality in early day care and preschool experience continues. International Journal of Behavioral Development, 25(1), 1-6.

Oliveira, M. A.; Furtado, R. A.; Souza, T. N. \& Carvalho, M. I. C. (2003). Avaliação de ambientes educacionais infantis. Paidéia - Cadernos de Psicologia e Educação, 13(25), 41-58.

Palacios, J. (1990). Parents' ideas about the development and education of their children - Answers to some questions.
International Journal of Behavioral Development, 13, 137155.

Russel, A. (1997). Individual and family factors contributing to mothers' and fathers' positive parenting. International Journal of Behavioral Development, 21(1), 111-132.

Sigolo, S. R. R. L.\& Biasoli-Alves.Z. M. M. (1998). Análise de dados de interação mãe-criança: Construção de sistemas de categorias. Em G. Romanelli \& Z. M. M. Biasoli-Alves (Orgs.), Diálogos Metodológicos sobre Prática de Pesquisa (pp. 87-118). Ribeirão Preto: Legis Summa.

Vieira, T.; Guimarães, L.; Toledo, F. C.; Reis, C. A \& Andrade, F. N. (2003). O adulto e o brincar no contexto da creche. Em Sociedade Brasileira de Psicologia (Org.), Anais da XXXIII Reunião Anual de Psicologia (p. 161). Belo Horizonte: SBP.

Enviado: 20.11 .2003 Revisado: 07.03.2004 Aceito: 07.05.2004

\section{Notas:}

${ }^{1}$ Do termo Authoritative em inglês, que significar ter autoridade sem ser autoritário.

Apoio financeiro / origem do trabalho: Este trabalho contou com o apoio da FAPESP.

\section{Sobre os autores:}

Profa. Dra. Lígia Ebner Melchiori - Departamento de Psicologia - Faculdade de Ciências - UNESP- Bauru -SP

Endereço para correspondência: Departamento de Psicologia - Unesp

Av. Luís Edmundo Carrijo Coube, s/n. - Bairro: Vargem Limpa

Bauru-SP CEP: 17033-360 - Endereço eletrônico: lmelch@ terra.com.br - Fax: (14) 3203-0562

Profa. Dra. Zélia Maria Mendes Biasoli Alves - Departamento de Psicologia e Educação - Faculdade de Filosofia Ciências e Letras de Ribeirão Preto - USP- Ribeirão Preto - SP 